\title{
Planning of expansion of ICU hospital care in times of Covid- 19 using the E2SFCA model
}

\section{Planificación de UCls en la atención hospitalaria en tiempos de CoVid-19 mediante el modelo E2SFCA}

\author{
ESCOBAR, Diego A. ${ }^{1}$ \\ CARDONA, Santiago ${ }^{2}$ \\ RUIZ, Santiago ${ }^{3}$
}

\begin{abstract}
The COVID-19 pandemic has put health systems around the world in check, so governments have arranged different options with the aim of reducing the number of infections, while strengthening the health system through expansion of the UCI offer. This research article evaluates the current ICU supply for every thousand inhabitants in the Manizales-Villamaría Metropolitan Area, considering the available hospital capacity, the average travel time to the hospital network.

key words: COVID-19, E2SFCA, potential spatial accessibility, planning, hospitals.

\section{Resumen}

La pandemia por el Covid 19 ha puesto los sistemas de salud alrededor del mundo en jaque por lo que los gobiernos han definido distintas opciones para reducir el número de infecciones mientras fortalecen los sistemas de salud a través de la expansión de Ucis. Esta investigación evalua la oferta actual de Ucis entre los habitantes de Manizales-Villamaría, considerando la capacidad disponible y el tiempo promedio de viaje a cada hospital a través de la red vial.

key words: COVID-19, E2SFCA, accesibilidad potencial, planeación, priorización, hospitals, ICU.
\end{abstract}

\section{Introduction}

COVID-19 is a disease caused by the SARS-CoV-2 virus first detected in Wuhan, China in early December 2019 (Wang et al., 2020). This virus is zoonotic, causing symptoms similar to those from the common flu, including runny nose, sore throat, cough, fever, and difficulty breathing in severe cases. Likewise, its transmission has been exponential reaching a large number of countries worldwide, causing the World Health Organization (WHO) to declare it as a pandemic, given the high degree of impact it can cause to developing countries, where health and hospital capacities are less than those of developed countries (World Health Organization, 2020a). According to the number of infections reported since its appearance $(2,549,632)$, the COVID-19 mortality rate worldwide is around $4.78 \%$, with peaks in countries such as Italy (13.39\%) and Spain (10.42\%). (World Health Organization, 2020b). On the other hand, the American continent has seen its contagion cases grow exponentially in recent weeks, making the United States the new focus of the pandemic $(800,926$ infections with $5 \%$ of mortality),

\footnotetext{
${ }^{1}$ Universidad Nacional de Colombia. Facultad de Ingeniería y Arquitectura, Departamento de Ingeniería Civil, Grupo de investigación en Movilidad Sostenible. Campus La Nubia, Bloque S2-208, Carrera 37 con Calle 94, Manizales, 170003, Colombia. (email: daescobarga@unal.edu.co)

2 Jóven Investigador. MSC en Ingeniería. Universidad Nacional de Colombia, Sede Manizales, Colombia. (email: scardonau@unal.edu.co)

3 Investigación en Innovación y Desarrollo Tecnológico. Carrera 27 \# 64-60, Manizales, 170004, Colombia. (e-mail: sruizhe@unal.edu.co)
} 
surpassing China. Likewise, Colombia currently has 4149 diagnosed cases (23/04/2020), with a mortality rate of $4.72 \%$, very near to the death rate worldwide. Despite the fact that social isolation measures have been taken to mitigate the growth in the number of infections, it is quite likely that the numbers related to the pandemic are far from reality, given the limitations in the health system and the speed of COVID-19 diagnosis (National Institute of Health, 2020).

Due to this problem, research teams around the world have prepared mathematical models that serve to forecast and exemplify the exponential infection that these types of diseases have (Ivorra , 2020). Knowing the collapse of the health systems caused by COVID-19 in developed countries such as Italy, Spain and the United States, Colombia must prepare to attend to the severe $(550,600)$ and critical cases $(187,523)$ that will result from the 3,989,853 infected will have, according to the projections of the National Institute of Health (2020). The capacity of the Colombian health system to face critical cases of COVID-19 reaches 5,320 beds in intensive care units (ICUs), of which only 150 have requirements for insulation and air filters (Colombian Association of Critical Medicine and Intensive Care, 2020). Thanks to this background, it was concluded that it is of great importance that national governments act to minimize deaths and reduce the inevitable economic impact through three main preventive measures (Anderson et al., 2020): i) quarantine, ii) social distance, iii) isolation of infcted populations, among others.

The concept of accessibility, which dates back to a century ago (Levine, 2020), seeks to measure the opportunities for interaction that an individual possesses through the use of an infrastructure network and various, complementary or not, transport systems as a maximum expression of the supply (Geurs \& Ritsema, 2001). Records of the use of the concept have been found, in urban and regional planning, since the first five-year period of the 20th century in predicting patterns of land use and transportation that stimulated physical development (Hurd, 1903). At the end of the third decade of the same century, Haig (1927) explained that the concept would serve urban planners in the future, to zoning the development of cities (Levine, 2020); however, it is not until the middle of that century that accessibility is defined in mathematical terms (Hansen, 1959). The concept has been constantly transformed (Batty, 2009; Ingram, 1971), addressing different measures (Pirie, 1979), perspectives (Handy \& Niemeier, 1997), and dimensions (Páez et al., 2012), finding that different authors have carried out interesting literature reviews around the concept, identifying its evolution (Levine, 2020). Throughout time, there have been examples of the use of the concept in areas such as: geospatial analysis of economic activities (Zuluaga \& Escobar, 2017), social equity in access to transport (Lucas et al., 2016), demographic analysis (Kotavaara et al., 2011), sustainability (Vega, 2011), operation of transport modes (Cui \& Levinson, 2019), educational infrastructure (Younes et al., 2016), etc.

Recognizing that accessibility is a primary need (Halden, 2011), urban planners have used it as an assessment measure of hospital care coverage (Wang et al., 2020) and ambulance dispatchers (Holguín et al., 2018), including to this extent, the social dimensions present in a territory (Moorin \& Holman, 2006). Accessibility depends both on the service delivery system, the spatial distribution of the population that demands it (Aday \& Andersen, 1974) and on the operational characteristics of the transport network (mode of transport, operational speeds, etc.) (Dummer \& Parker, 2004). Taking into account that accessibility to medical facilities is an extremely important multidimensional variable, it has been applied in different studies such as: the use of the health system by the elderly population (Love \& Lindquist, 1995), risk of mortality and asthma (Dummer \& Parker, 2004), use of the system according to economic capacity (Moorin \& Holman, 2006) and reorganization of hospital services (Kalogirou \& Foley, 2006), among others. In addition, in recent decades the development of new computer tools such as geographic information systems (GIS) have allowed the spatial location of services to be related to databases of sociodemographic and socio-economic characteristics (Ahmed, Adams, Islam, Hasan, \& Panciera, 2019). Conceptually, it is possible to classify the measures of "access" to the health service provider system into four types: i) potential spatial accessibility (geographical distribution of health services and population), ii) 
potential non-spatial accessibility (affordability, acceptability or adequacy), iii) declared spatial accessibility, iv) declared non-spatial accessibility (possession of health insurance) (Luo \& Whippo, 2012). To measure spatial accessibility, different models have been proposed, such as regional availability (Khan, 1992), gravity-model (Joseph \& Bantock, 1982), kernel density (Guagliardo, 2004) and floating catchment area models (Luo \& Wang, 2003). Despite the diversity of models with a regional focus, some of these may lead to an overvaluation of service accessibility values in some areas and an underestimation in others, which means that specific efforts to improve access to mentioned service may be erroneously addressed (Luo \& Qi, 2009). Considering this, measures based on gravity models were developed (Joseph \& Phillips, 1984) that together with GIS tools have allowed calculating the relationship between the supply of health care services and the population that demands such services (Pan et al., 2015). However, these models have the disadvantage of generating low interpretability, reducing the attention of the entities that must make specific punctual decisions. Therefore, various types of measurement have been developed within the framework of the so-called Floating Catchment Area (FCA), which provide alternative approaches, based on GIS, to calculate spatial accessibility to health.

The FCA measures are based on the gravity model, integrating the mathematical capacity with an improvement in the interpretation of the result by having easy to understand units (number of beds, doctors or hospitals per inhabitant). The first implementation of this type of metrics was the so-called two-Step Floating Catchment Area method (2SFCA) (Radke \& Mu, 2000), which, unlike regional availability methods, allow the catchment area to fluctuate depending of the distance according to the disposition of the users to carry out the displacement. In terms of health care, the response time to an event is directly related to the chances of survival (Neutens, 2015), which is why in the FCA models a catchment area is defined (McGrail \& Humphreys , 2014) in terms of distance or time. Studies have been found related to catchment areas of $30 \mathrm{~km}$ (Luo \& Wang, 2003), $3 \mathrm{~km}$ in urban areas (Shah et al., 2016) or 60 minutes and 30 minutes (Wan et al., 2012 ); in general, the debate around the size of catchment areas continues (Wan et al., 2012). However, there are important advances in this regard (Whitehead et al., 2020), given that it is real that a person will move to one or the other hospital depending on a multiplicity of factors (time, distance, type of need, etc).

There are some modifications of the FCA method such as the three-step floating catchment area method (3SFCA) (Wan et al., 2012), the modified two-step floating catchment area method (M2SFCA) (Luo \& Wang, 2003), the enhanced two -step floating catchment area (E2SFCA) (Luo \& Qi, 2009) and the Variable 2SFCA method (V2SFCA) (Luo \& Whippo, 2012). The E2SFCA is the most widely used in planning analysis (Dewulf et al., 2013), without claiming that any of these methods perform better than the others (McGrail, 2012). There are examples of application in studies related to health of this type of models in Colombia (Monsalve et al., 2016; Rojas \& Caicedo, 2017), however, they are not commonly applied in the stages of planning the health services that communities need.

In this investigation, the hospital system of the Manizales-Villamaría Metropolitan a Area (Colombia) is studied (Figure 1). Manizales is the capital of the Caldas department, located in the western center of Colombia on the central mountain range (2150 masl average), with a steep and abrupt topography that makes its urbanization and expansion processes difficult (Cardona, 2018). It is surrounded by the population of Villamaría and combined, they host a population of 423,278 inhabitants by 2020 (DANE, 2018). There are two main reasons for choosing the Manizales-Villamaría conurbation as a study area (See Figure 1): i) most public policies related to financial support for health care are carried out at the municipal level; ii) the results can support future joint policy-making efforts and the allocation of health resources in the future metropolitan region of the south central region. Potential spatial accessibility is calculated by applying the enhanced two-step floating catchment area (E2SFCA). However, taking into account the measures of potential spatial access must be related to the real possibility of use (Aday \& Andersen, 1974). In this research, we relate the results obtained with data on the need for use by the percentage of the population that probably will get infected with COVID-19. 
Figure 1

Location of Manizales - Villamaría Metropolitan Area.

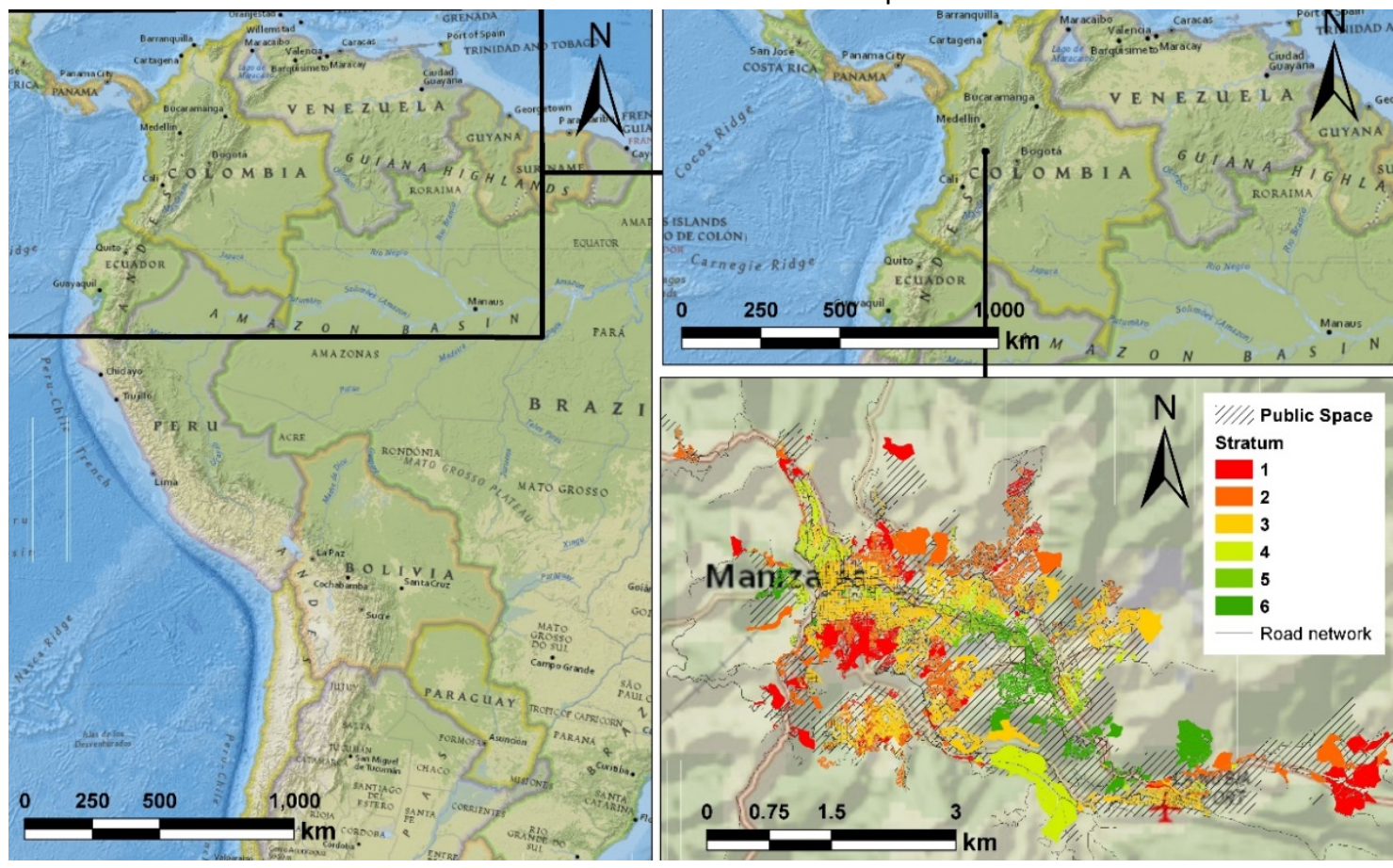

Source: Adaptation from Esri.

Thus, using GIS tools, and based on sociodemographic data of the population, location of hospitals and analysis of the transport infrastructure network, we carried out the calculation of the conditions of potential spatial accessibility to hospitals that have availability of Intensive Care (ICU), to care for critically ill patients affected by COVID-19. The research addresses three scenarios of potential spatial accessibility: i) based on the availability of ICU at present; ii) based on the number of ICUs that the municipal administration intends to expand into three hospitals in the city; iii) based on new ICUs that should be located in sites where the need to improve potential spatial accessibility values is identified. With the accessibility results in each scenario, a statistical comparison is made, and they are related to the socioeconomic stratum of each studied area. The strata are a classification of the population according to their socioeconomic condition in a hierarchical way, a classification used in Colombia for planning purposes; there are six strata, with 1 being the one with the lowest economic capacity and 6 the one with the highest capacity (Escobar et al., 2019). The research article continues as follows. After the introduction, the research methodology is explained in detail, describing the minimum data necessary for its development and replication. Afterwards, the results are listed followed by a discussion. Finally, the main conclusions are presented.

\section{Methodology}

The research methodology addressed consists of four main phases (Figure 2), which are summarized below.

\subsection{Collection of Information, Phase 1}

The investigation is fully supported by secondary information, collected from databases related to: i) Projection of COVID-19 contagion cases defined in Decree 417 of March 17, 2020, by which a State is declared Economic, Social and Ecological Emergency in all the national territory, issued by the Presidency (Republic of Colombia, 2020); ii) Sociodemographic data layer of the Manizales-Villamaría Metropolitan Area with information on neighborhoods, inhabitants by neighborhood, socioeconomic stratum, among other variables; iii) Layer of the 
transport infrastructure network, which complies with the graph theory when evaluating its performance through its main topological components, nodes (road intersections), arcs (roads), with information on its physical components (length and slope) and operating components (speed); iv) layer with the geographical location (latitude, longitude) of the hospitals with an (ICU) service, intermediate and single beds, establishing the number of units available. All collected geographic information is reviewed, adjusted and updated.

Figure 2

Research Methodology

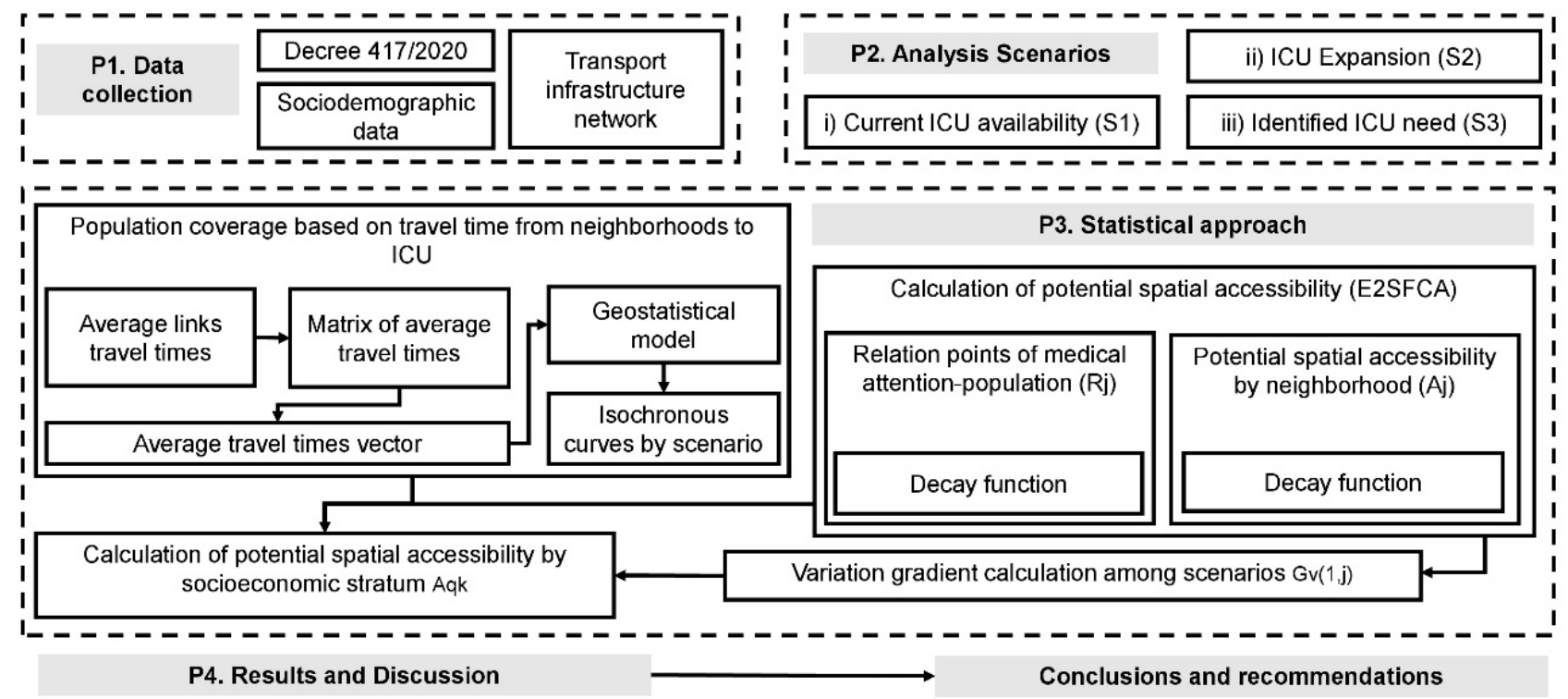

Source: Authors

\subsection{Analysis Scenarios, Phase 2}

To assess the conditions of accessibility to the health system in this time of pandemic, three analysis scenarios have been defined for the research: i) based on the current availability of the ICU (142); ii) based on the current ICU capacity available (142), plus the number of new ICUs (160) that will be adapted by the municipal administration in three city hospitals; iii) based on the number of ICUs in scenario 2 (302), newer ICUs (58) located in sites where the need to improve accessibility values has been identified, based on the gradient analysis between scenario 1 and scenario 2 (see 2.3.3.). A total of 360 ICUs are taken as the maximum limit since this is the value of units that the mayor's office can adapt and/or install. For the three analysis scenarios, the percentage of possible infected people needing care in the ICU has been calculated from the values projected by the Presidency of the Republic and defined by Decree 417 of March 17, 2020, which establishes that 7.92\% of the Colombian population (3,998,853 inhabitants) will get COVID-19, of which $18.5 \%$ (738,123 inhabitants) will need ICU care; This means that $1.47 \%$ of the Colombian population will need highly complex care. Now, for the calculations of potential spatial accessibility of the three scenarios, it will be assumed that $1.47 \%$ of the population of the Manizales-Villamaría Metropolitan Area would need ICU care (6200 potential patients).

\subsection{Statistical approach, Phase 3}

This is made up of the following sub-stages: i) Calculation of the coverage conditions in average travel time through the transport infrastructure network in relation to the geographical location of the hospitals with ICUs and calculation of the percentages of population coverage by socioeconomic stratum; ii) Application of the E2SFCA method to define the conditions of access to the medical service based on the location of the population, the number of ICUs available per hospital and the Gaussian function of decay of the average travel time, for the 
three scenarios; iii) Calculation of the gradient between scenarios; iv) Calculation of potential spatial accessibility by socioeconomic stratum.

\section{Population coverage based on travel time from neighborhoods to ICU Hospitals.}

In this sub-step, the average travel time between each pair of nodes is calculated by the relationship between length and speed over an arch, $t_{v i}=l_{i} / v_{i}$, where: $\mathrm{i}$ is the arch in question, $\mathrm{t}_{\mathrm{vi}}$ is the travel time for arch $\mathrm{i}, \mathrm{l}_{\mathrm{i}}$ is the length of arch $i$ and $v_{i}$ is the speed of arch $i$; the speeds with which the network was loaded were the maximum speeds allowed according to the type of road, $60 \mathrm{Kph}$ for main and secondary roads, and $30 \mathrm{Kph}$ for local roads. Hypothetically, the streets are decongested given the characteristics of the established quarantine, which would allow a vehicle that needs to transport a patient to do so probably at these speeds. With the arch travel times, the Dijkstra (1959) algorithm of minimum paths is applied, which is included in the Network Analyst extension of ArcMap and through which the mean travel time vector (Tvi) is obtained as follows:

$$
\overline{T_{v l}}=\frac{\sum_{j=1}^{m} \sum_{i=1}^{n} t_{v i j}}{\mathrm{~m}} \quad i=1,2,3, \ldots, n ; j=1,2,3, \ldots, \mathrm{m}
$$

Where, tvij is the minimum travel time from each of the nodes (i) that make up the road network, to each of the hospitals ( $\mathrm{j}$ ) with ICU bed availability, $\mathrm{n}$ is the total number of nodes in the network and $\mathrm{m}$ It is the total number of hospitals, taking into account the corresponding turn penalties in the model. Subsequently, each of the nodes in the network is assigned the corresponding coordinates, reaching the vector of average travel times, which is a necessary input for the construction of isochronous curves using the ordinary Kriging geostatistical model with a linear semivariogram as structuring equation (Moncada et al., 2018). Ordinary Kriging with linear semivariogram was used as a geostatistical model. Through this model, more accurate approximations and less errors have been obtained when the distance between points to interpolate is short (Li \& Heap, 2008), as in the urban network studied. The spatial autocorrelation level of the dataset relies on three semivariogram variables: the nugget effect, range, and sill. The semivariogram characterizes the properties of spatial dependency between values of an observed sample dataset, which is calculated as:

$$
\overline{\gamma_{(h)}}=\frac{\sum\left(\mathrm{Z}_{(\mathrm{x}+\mathrm{h})}-\mathrm{Z}_{(\mathrm{x})}\right)^{2}}{2 \mathrm{n}}
$$

Where, $Z(x)$ is the value of the variable in a site with $x, y$ coordinates. $Z(x+h)$ is another sample value separated by a distance $h, n$ is the number of couples that are separated by that distance $h$. This method has been used previously by researchers for issues such as demand prediction for public transport systems (Prasetiyowati, Imrona, Ummah, \& Sibaroni, 2016) After calculating the isochronous curves, these are related to the sociodemographic variables, area, population and socioeconomic stratification by crossing the information using the ArcMap "Geoprocessing" extension; the management of the data obtained is carried out using Microsoft Excel and the corresponding percentage coverage warheads are constructed.

\section{Calculation of potential spatial accessibility by the E2SFCA method}

To calculate the potential special accessibility, a model was developed based on the E2SFCA method (Luo \& Qi, 2009), by developing two consecutive steps, the first related to the supply of health care points and the second related to demand of attention by the population.

\section{Step 1: Calculation of the ratio of Medical Care Points - Population}

Based on detailed knowledge of the Manizales-Villamaría Metropolitan Area, a catchment area of 15 minutes per hospital is defined, a value that is in the range of 5 minutes, minimum time for emergency care (Neutens, 2015) and 30 minutes, standard travel time recommended in health plans (Pan et al., 2015). The catchment area was divided into three subzones (0-5, 5-10, and 10-15 min.) (See Figure 4). Each subzone is assigned different 
weights based on the decay function $f(d)$, which can be adjusted depending on the travel pattern related to a certain service. For this case study, the critical patient care service by COVID-19. F. Wang (2012) defines six distance decay functions for the case of a patient-hospital travel pattern (gravity function, Gaussian function, binary discrete, multiple discrete, kernel density, and three-zone hybrid). In this investigation, the Gaussian decay function $f(d)=\exp \left(-t_{i j}^{2} / \beta\right)=w_{r}$, is used, taking into account that it is considered the most appropriate to simulate this distance effect (Kwan, 1998). Where $B$ is the impedance coefficient that indicates the percentage of the population that would be willing to make a trip to be attended by a health service, and, $y t_{i j}$ is the average travel time between a point and a hospital. Now, considering the suggestion of F. Wang (2012) that 0.01 is a critical point where the Gaussian function approaches zero, and having defined 15 minutes as the floating catchment area, the used value for 6 was 34 . The relation points of medical attention - population is denoted as $R_{j}$ and is calculated as follows:

$$
R_{j}=S_{j} / \sum_{k \in\left\{t_{k j} \in T_{r}\right\}} P_{k} * w_{r}=S_{j} /\left(\sum_{k \in\left\{t_{k j} \in T_{1}\right\}} P_{k} * w_{1}+\sum_{k \in\left\{t_{k j} \in T_{2}\right\}} P_{k} * w_{2}+\sum_{k \in\left\{t_{k j} \in T_{3}\right\}} P_{k} * w_{3}\right)
$$

Where, $P_{k}$ is the population that is within the catchment area of each hospital (j) $\left(t_{k j} \in T_{r}\right), S_{j}$ is the number of beds available (ICU according to the calculation scenario) in each hospital (j), $t_{k j}$ is the mean travel time between the population ( $k$ ) and the hospital $(\mathrm{j}), T_{r}$ are the travel time subzones that make up the catchment area $(r=1-3)$, and $w_{r}$ is the weight assigned for each subzone from the Gaussian decay function of the access distance to each hospital (j). With the definition of the FCA related to the supply of health care points, it is necessary to involve the distance decay function, since not doing so, would be accepting that the probability that a health care point could provide services to the population that lives near and to the population that lives further away, is the same, which is not real, since the distance at which a service is found influences the decision to use it, especially if there is competition between points that provide the same kind of care.

\section{Potential Spatial Accessibility by neighborhood}

The Manizales-Villamaría Metropolitan Area has 122 neighborhoods; for each neighborhood (i), all the hospitals (j) that are located within each of the sub-areas of the catchment area are identified $\left(T_{r} ; r=1-3\right)$, and knowing the ratio of medical care points-population $\left(R_{j}\right)$, the potential spatial accessibility $\left(A_{i}\right)$ of each neighborhood to each health service is calculated (availability of ICU, in this case), as follows:

$$
A_{i}=\sum_{j \in\left\{t_{i j} \in T_{r}\right\}} R_{j} * w_{r}=\sum_{j \in\left\{t_{i j} \in T_{1}\right\}} R_{j} * w_{1}+\sum_{j \in\left\{t_{i j} \in T_{2}\right\}} R_{j} * w_{2}+\sum_{j \in\left\{t_{i j} \in T_{3}\right\}} R_{j} * w_{3}
$$

Where, $t_{i j}$ is the average travel time between a neighborhood (i) and a hospital (j); likewise, the same weights are applied that each one of the sub-zones refers given the Gaussian Function of distance decay used in step 1. The population seeking some kind of care would also be influenced by the distance decay function, since not doing so would be accepting that a person in a neighborhood would be just as willing to go to any point of medical care without influencing their decision on the proximity of the hospital in time.

\section{Variation $\boldsymbol{G}_{\boldsymbol{v}(\mathbf{1}, j)}$}

This calculation allows a percentage comparison between the potential spatial accessibility values $\left(A_{i}\right)$ of each neighborhood, obtained in each of the three studied scenarios (Escobar et al., 2019). The foregoing with the objective of establishing in which neighborhoods of the study area the greatest or least impact is presented in 
relation to the improvement in the availability of ICU and the greatest number of medical attention points. The gradient of variation among scenarios $G_{v(1, j)}$, is calculated as follows:

$$
G_{v(1, j)}=\left[\left(A_{i, S C_{p}}-A_{i, S C_{1}}\right) / A_{i, S C_{p}}\right] * 100
$$

Where $A_{i, S C_{1}}$ is the potential spatial accessibility value for each neighborhood in scenario 1 , and $A_{i, S C E_{j}}$ the potential spatial accessibility value for each neighborhood in each scenario $p(2$ y 3 ) corresponding.

\section{Potential Spatial Accessibility by socioeconomic stratum}

As a methodological input prior to calculating the average number of ICU beds by socioeconomic stratum, the results obtained from the analysis of the average travel time from the neighborhoods to the ICU hospitals (Phase 1) are incorporated for the three scenarios. Subsequently, these population values are linked by time range, using the ArcMap tool, through its Geoprocessing - Intersect extension, to the potential spatial accessibility values by neighborhood $\left(A_{i}\right)$, distributed according to the socioeconomic stratum, as presented in the following equation, $A_{i q}=\left(P_{i q} * A_{i}\right) / P_{i}$, where $A_{i q}$ is the potential spatial accessibility value in the neighborhood (i) for the stratum (q) and $P_{i q}$ is the total population of the neighborhood (i) in the stratum (q). With the results produced by the ArcMap Tool, dynamic tables are constructed in the Microsoft Excel tool, by which the average values of beds per thousand inhabitants, associated with the socioeconomic strata, are calculated at the travel time intervals in relation with hospitals with ICU availability. The calculation is made with the following equation:

$$
\overline{A_{q k}}=\left(\sum_{k}^{n} \sum_{i}^{m} A_{i q}\right) / N_{k}
$$

Where $\overline{A_{q k}}$ is the accumulated average value of the potential spatial accessibility for stratum (q) (1 - 6) in the time interval $k, \in\left\{t v_{0}: t v_{1} ; t v_{0}: t v_{2} ; \ldots ; t v_{0}: t v_{n}\right\}, A_{i q}$ is the potential spatial accessibility value in the neighborhood (i) for the stratum (q) and $N_{k}$ is the number of qualification fields in the interval (k). Finally, the average values of beds for each socioeconomic stratum are tabulated, in which the qualifications of the previous time intervals are contemplated, allowing the accumulated coverage curves to be generated, by relating the accumulated number of ICUs available per thousand inhabitants with the average travel time, for each socioeconomic stratum.

\subsection{Analysis of results, Phase 4}

In this final phase, the results are compared both from the geographical point of view and from the quantitative point of view, in relation to the variation in the potential spatial accessibility values by neighborhood and by stratum; on the other hand, these are compared with the values of population coverage by stratum in terms of average travel times to hospitals. On the other hand, the values obtained with those found in official reports on the number of beds per inhabitant will be analyzed in cities with a population size similar to that of the study area. This comparison will allow to support the discussion and conclusions of the investigation.

\section{Results and discussion}

The Figure 3, shows the population density of the study area together with the geographical location of the 15 analyzed hospitals. In this case, it is observed how the northern part of the city has high densities (500 - 1000 inh./Ha), coinciding with the sectors of a low socioeconomic stratum. On the other hand, areas with density 0 are equivalent to environmental protected areas. The Table 1, presents a list of the studied hospitals, as well as their geographical coordinates and the number of ICU beds available in each of them, for each studied scenario. 
Figure 3

Population Density per Hectare and Location of Hospitals in the Study Area.

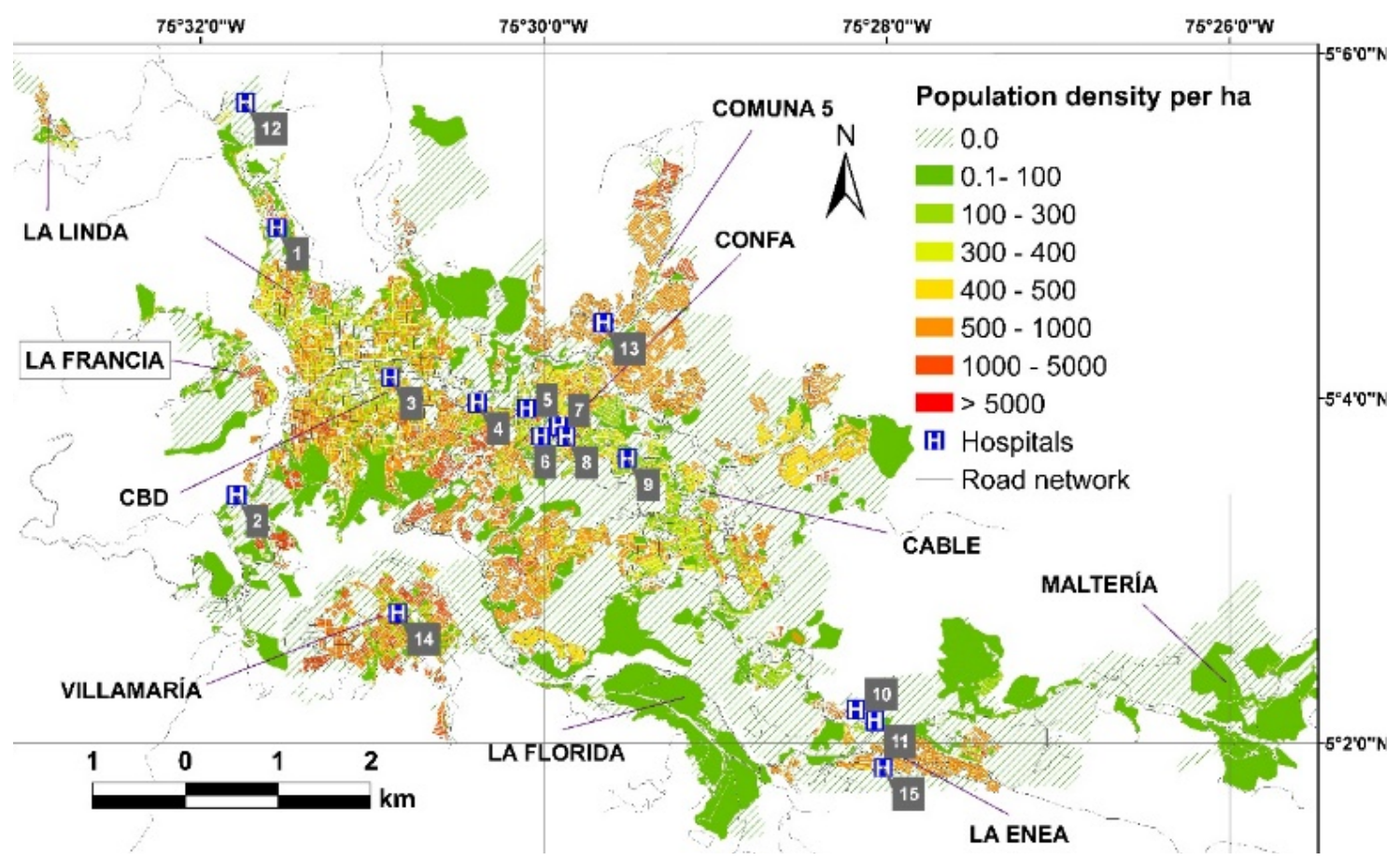

Source: Authors

Table 1

Hospitals: Geographical Coordinates and ICU Beds by Setting

\begin{tabular}{|c|l|c|c|c|c|c|}
\hline \multirow{2}{*}{ ID } & \multirow{2}{*}{ Hospital } & \multicolumn{2}{|c|}{ Coordinates } & \multicolumn{3}{c|}{ Number of ICU beds } \\
\cline { 2 - 7 } & & Longitude & Latitude & Scenario 1 & Scenario 2 & Scenario 3 \\
\hline 1 & Avidanti & -75.5259389 & 5.0831754 & 37 & 97 & 97 \\
\hline 2 & Sta. Sofía & -75.5298472 & 5.0573224 & 27 & 27 & 27 \\
\hline 3 & Aman & -75.5148853 & 5.06868591 & 7 & 7 & 7 \\
\hline 4 & Meintegral & -75.5064343 & 5.06624864 & 10 & 10 & 10 \\
\hline 5 & La Presentación & -75.5016753 & 5.0656892 & 7 & 7 & 7 \\
\hline 6 & SES & -75.500282 & 5.0630347 & 18 & 58 & 58 \\
\hline 7 & Infantil & -75.4985909 & 5.06398303 & 4 & 4 & 4 \\
\hline 8 & Versalles & -75.4978348 & 5.0629916 & 14 & 14 & 14 \\
\hline 9 & Santillana & -75.4918725 & 5.06084285 & 6 & 6 & 6 \\
\hline 10 & Oncólogos & -75.4696854 & 5.03657587 & 6 & 6 & 6 \\
\hline 11 & San Marcel & -75.4678539 & 5.03551782 & 6 & 66 & 66 \\
\hline 12 & San Isidro & -75.5289869 & 5.09525054 & 0 & 0 & 8 \\
\hline 13 & San Cayetano & -75.4942106 & 5.0739775 & 0 & 0 & 10 \\
\hline 14 & San Antonio & -75.5141645 & 5.04589662 & 0 & 0 & 20 \\
\hline 15 & La Enea & -75.4670355 & 5.03095141 & 0 & 0 & 20 \\
\hline
\end{tabular}

Source: Authors 
Along the west-east axis, in the geographical center of the city, 7 hospitals are located, among which $46.5 \%$ of the total ICU supply is concentrated, for scenario 1. On the other hand, the north-western sectors (La Linda) and south (Villamaría) do not currently have ICU availability, which generates greater vulnerability in matter. In the case of scenario 2, the offer is increased by 160 ICU beds, more than double the current offer (142); however, it is concentrated in current hospitals (1, 6 and 11), leaving aside areas of the city in need of ICU, which are analyzed in the third scenario when 58 additional beds are generated, in hospitals 12 to 15, located to the north-west, north, south and southeast. The Figure 4, shows the average travel time from the neighborhoods of the study area to the San Marcel hospital (east).

Figure 4

Average Travel Times from Each Neighborhood

to San Marcel Hospital

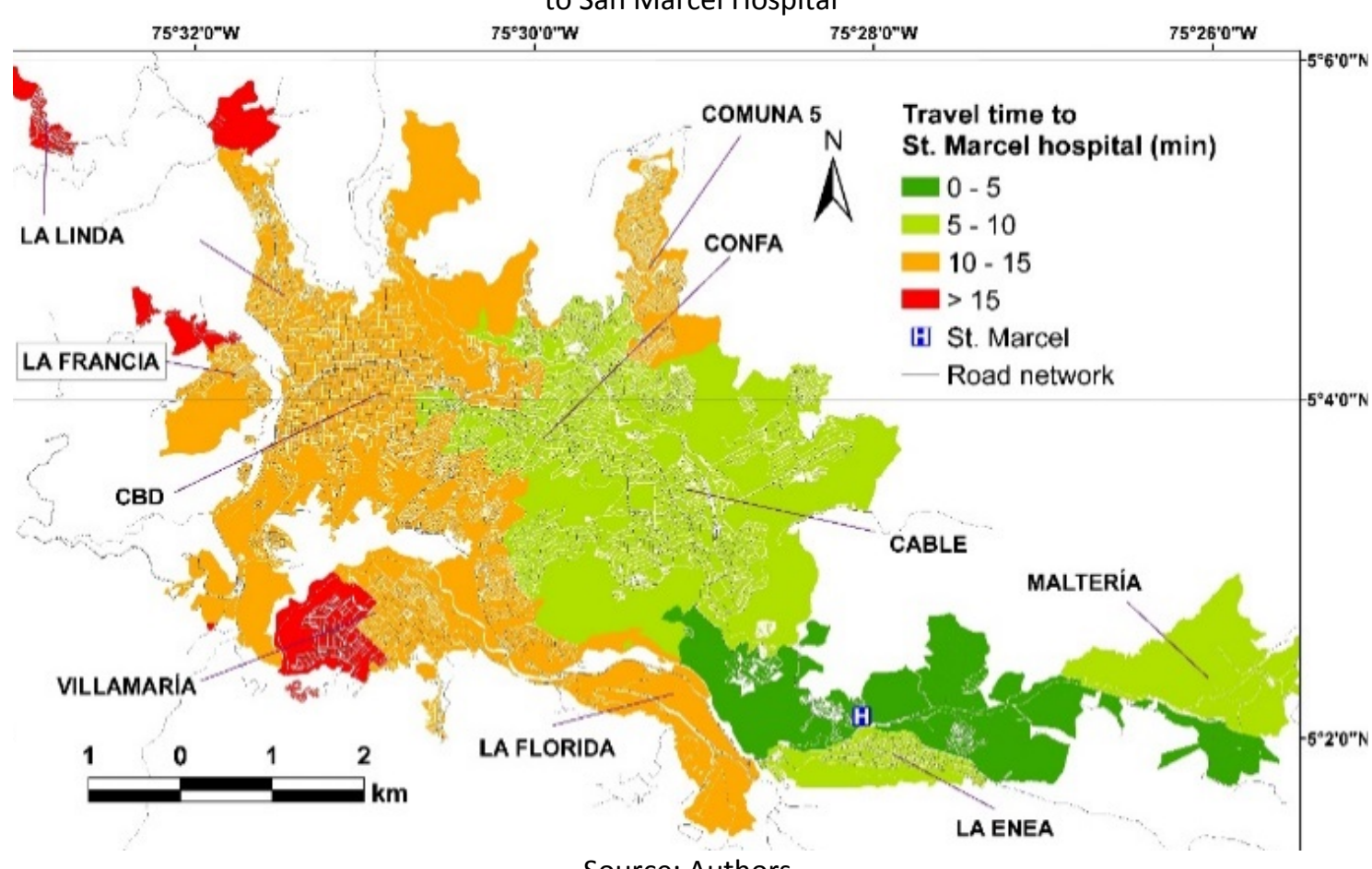

Source: Authors

The subzones of the catchment area are observed (0-5, 5-10, 10-15 minutes), identifying that towards said hospital there is a portion of the population that registers average travel times greater than 15 minutes, western sector (La Linda and La Francia) and south (Villamaría), therefore, taking into account that they would be outside the established catchment area, the referenced population would not be involved in calculating the ratio of medical care points - population $(\mathrm{Rj})$ of the hospital St Marcel $\left(\mathrm{R}_{11}\right)$.

The average travel times from each neighborhood (i) to each hospital (j) were used to calculate the ratio of medical care points-population ( $\mathrm{Rj})$, that is, the ICU offer of the hospitals. The average travel times can be consulted in the dataset attached with the investigative article. Table 2 shows the results of the relationship between medical care points and population (Rj) of each hospital in the different scenarios in ICU units per thousand inhabitants. For this calculation, only the percentage of the population that would probably need ICU care was considered, given their severe or critical conditions caused by COVID-19. It was found that for scenario 1, among the five hospitals with the highest Rj are Avidanti, Sta. Sofia, Oncologos, San Marcel and SES, between the first two, they reach 35.51 ICU / 1000 inhabitants and both are located west of the city. In scenario 2, they are the same hospitals that occupy the first five positions, but in different order. For Scenario 3, two of the hospitals identified as essential are located in the third (San Antonio) and fifth (La Enea) places. Figure 5 shows 
the results of potential spatial accessibility to the ICUs per thousand inhabitants, for each neighborhood in the study area, according to the ICU offer in the first scenario.

Table 2

Supply by hospital according to the Scenario, ICU for Every Thousand Inhabitants.

\begin{tabular}{|c|c|c|c|c|}
\hline \multirow{2}{*}{ ID } & \multirow{2}{*}{ Hospital } & \multicolumn{3}{|c|}{ Rj (UCl per 1000 inhabitants) } \\
\cline { 3 - 5 } & & Scenario 1 & Scenario 2 & Scenario 3 \\
\hline 1 & Avidanti & $\mathbf{( 1 )} 21.97$ & $\mathbf{( 2 )} 57.59$ & $\mathbf{( 2 )} 57.59$ \\
\hline 2 & Sta. Sofía & $\mathbf{( 2 )} 13.54$ & $\mathbf{( 4 )} 13.54$ & 13.54 \\
\hline 3 & Aman & 2.29 & 2.29 & 2.29 \\
\hline 4 & Meintegral & 3.39 & 3.39 & 3.39 \\
\hline 5 & La Presentación & 2.18 & 2.18 & 2.18 \\
\hline 6 & SES & $\mathbf{( 5 )} 6.15$ & $\mathbf{( 3 )} 19.82$ & $\mathbf{( 4 )} 19.82$ \\
\hline 7 & Infantil & 1.30 & 1.30 & 1.30 \\
\hline 8 & Versalles & 4.76 & 4.76 & 4.76 \\
\hline 9 & Santillana & 2.35 & 2.35 & 2.35 \\
\hline 10 & Oncólogos & $\mathbf{( 3 )} 9.71$ & $\mathbf{( 5 )} 9.71$ & 9.71 \\
\hline 11 & San Marcel & $\mathbf{( 4 )} 8.80$ & $\mathbf{( 1 )} 96.82$ & $\mathbf{( 1 )} 96.82$ \\
\hline 12 & San Isidro & 0.00 & 0.00 & 11.10 \\
\hline 13 & San. Cayetano & 0.00 & 0.00 & 14.57 \\
\hline 14 & San Antonio & 0.00 & 0.00 & $\mathbf{( 3 ) ~} 20.07$ \\
\hline 15 & La Enea & 0.00 & 0.00 & $\mathbf{( 5 )} 18.05$ \\
\hline
\end{tabular}

Source: Authors

Figure 5

Potential Spatial Accessibility

to ICUs. Scenario 1

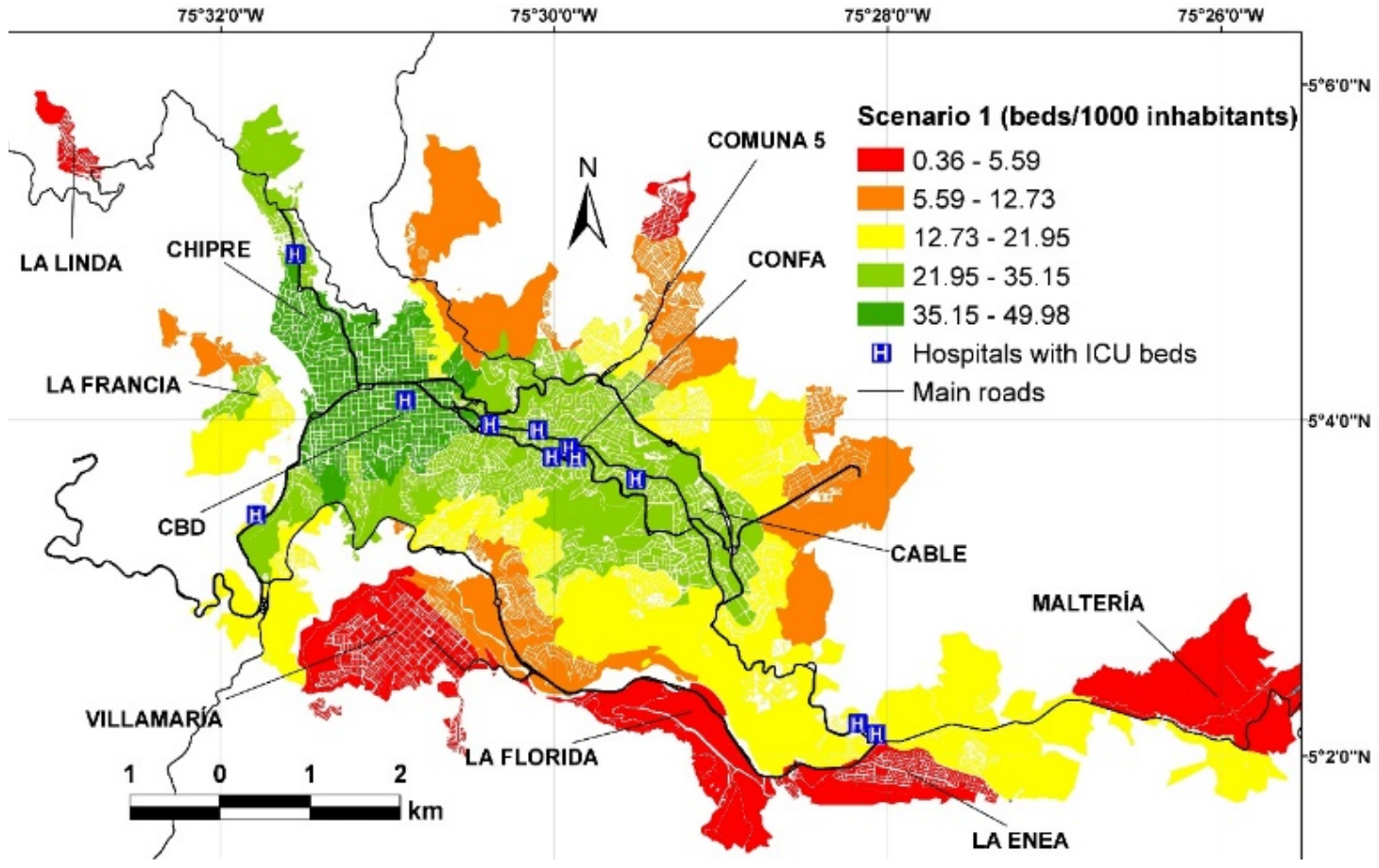

Source: Authors 
It is observed that the 11 hospitals that currently have ICU availability (142), are located on main routes, with a higher density of these towards the sector called "Confa" (center of figure 5). It was found that the lowest potential spatial accessibility value is between 0.36 and 5.59 ICU per thousand inhabitants (red color) and is registered in the neighborhoods located to the south (Villamaría, La Florida and La Enea), to the east (Maltería), to the north-west (La Linda) and north (Comuna 5) of the study area, their common denominator is their peripheral location. The maximum potential spatial accessibility value is between 35 and 50 ICUs per 1,000 inhabitants and is located in the city's CBD; the sector with better accessibility conditions (green) that expands to the north-west.

The Figure 6, shows the results related to the second scenario, in which 160 ICUs are increased in three city hospitals: Avidanti (60 ICU), SES Caldas (40 ICU) and San Marcel (60 ICU). In this case, the minimum supply increases to $0.5 \mathrm{ICU}$ for every thousand inhabitants and the maximum to $107.82 \mathrm{ICU}$ for every thousand inhabitants. In a wide extension of the territory, the offer is improved in this scenario, however, some of the peripheral areas continue to have accessibility problems to this medical service, Villamaría (south) and La Florida (south).

The Figure 7, presents the results of calculating the gradient of variation between scenarios 1 and 2 . It is observed that, given the ICU expansion proposal made by the mayor's office, which focuses on three hospitals, it is the eastern sector of the city that would achieve the greatest increases in the value of potential spatial accessibility in terms of the ICU offer per thousand inhabitants, an increase between $241 \%$ and $470 \%$. Likewise, the western and northern zones are the ones that perceive the least improvement. However, it is found that the entire study area perceives some type of improvement in the referenced potential spatial accessibility value, the lowest value of which is an improvement of $38 \%$ in relation to the accessibility value of scenario 1.

The Figure 8, shows the results of potential spatial accessibility by neighborhood obtained for scenario 3 . In this scenario, 58 new ICUs were distributed in 4 hospital centers (Magenta), reaching 360 ICUs in the city, the declared maximum capacity for expansion. by the municipal mayor's office. The selection of the four hospital centers in which it is proposed to install the new ICU was made taking into account the neighborhoods with the lowest accessibility value for scenarios 1 and 2 (Figure 5 and Figure 6) and which did not have high values in the gradient (Figure 7). In this case, the minimum supply increases considerably to 9.44 ICU for every thousand inhabitants, as well as the maximum supply that reaches 116.75 ICU for every thousand inhabitants.

The peripheral areas achieve better potential spatial accessibility values, with Villamaría (south), La Linda (northwest) and La Comuna 5 (north) as the greatest beneficiaries. In the gradient between scenario 2 and 3 (See figure 9), it is observed how there were changes in Villamaría (south) of up to $3368 \%$, which indicates that the ICU supply for every thousand inhabitants in the metropolitan municipality multiplied by 33 approximately. Likewise, Comuna 5 perceives an improvement in the supply of up to $337.72 \%$ and La Linda and La Enea of up to $129.34 \%$, indicating that the offer was distributed in areas where the impact was widely perceived. 
Figure 6

Potential spatial accessibility to icus

Scenario 2

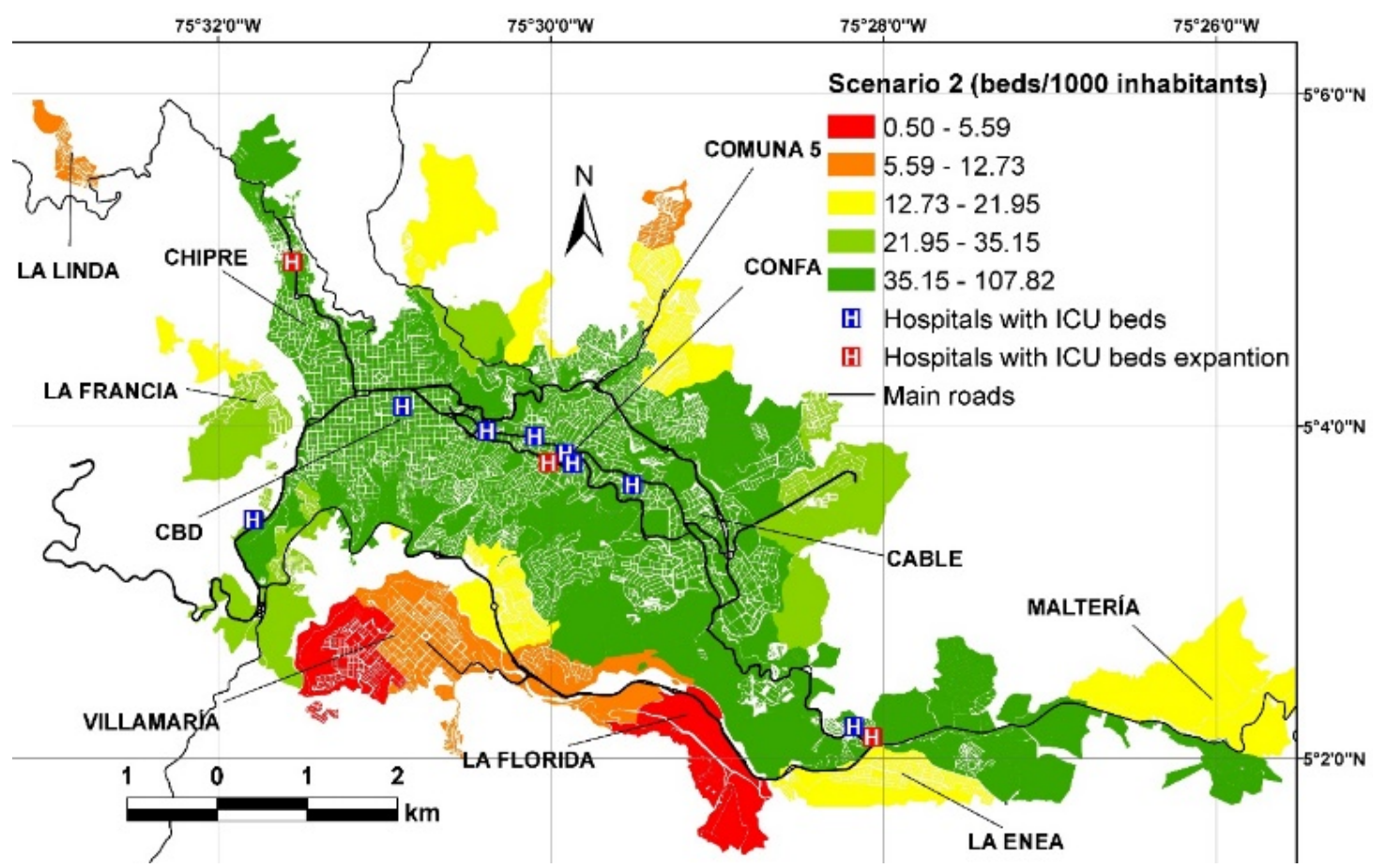

Source: Authors

Figure 7

Potential spatial accessibility gradient

between scenario 1 and scenario 2

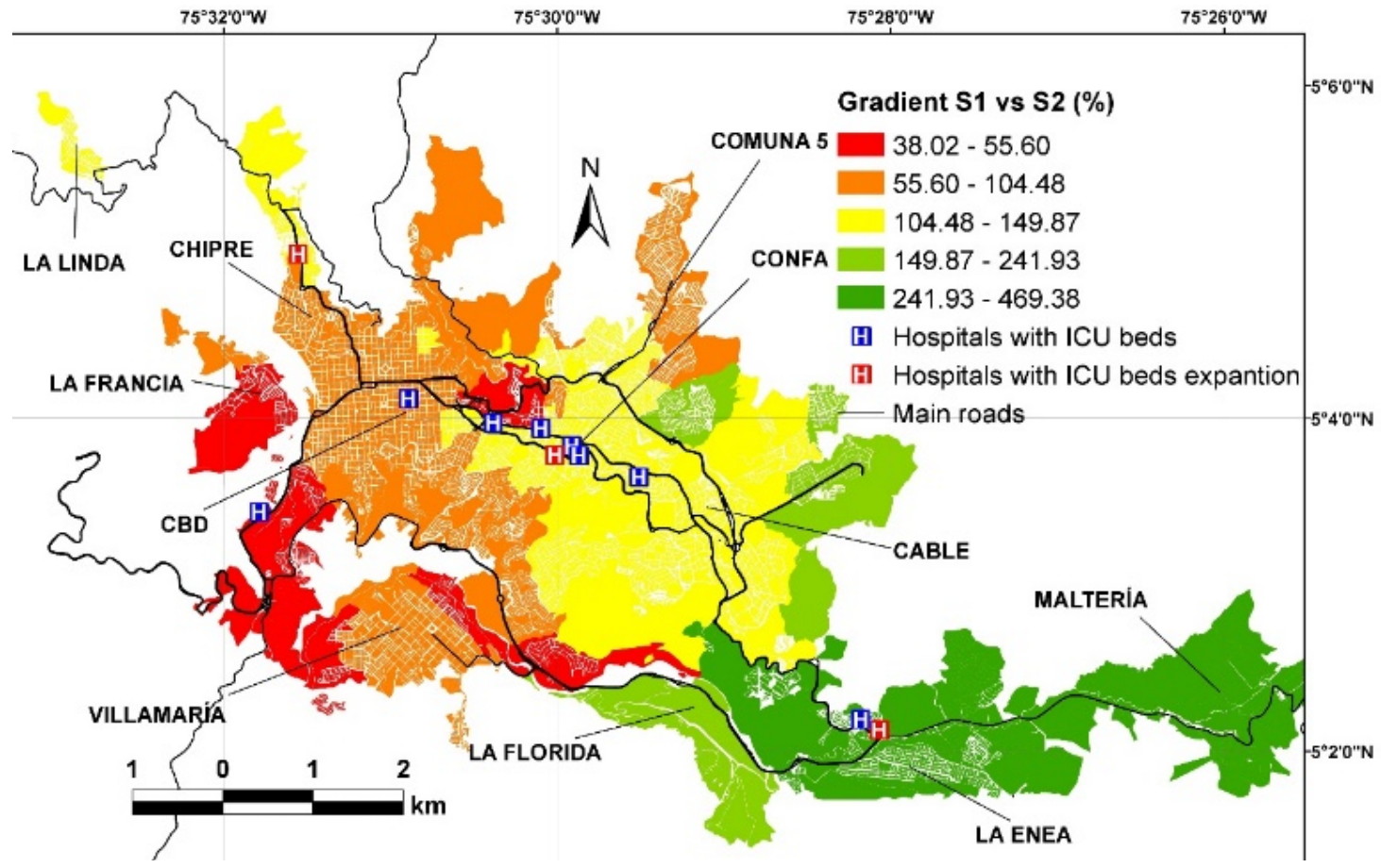

Source: Authors 
Figure 8

Potential spatial accessibility to icus

Scenario 3

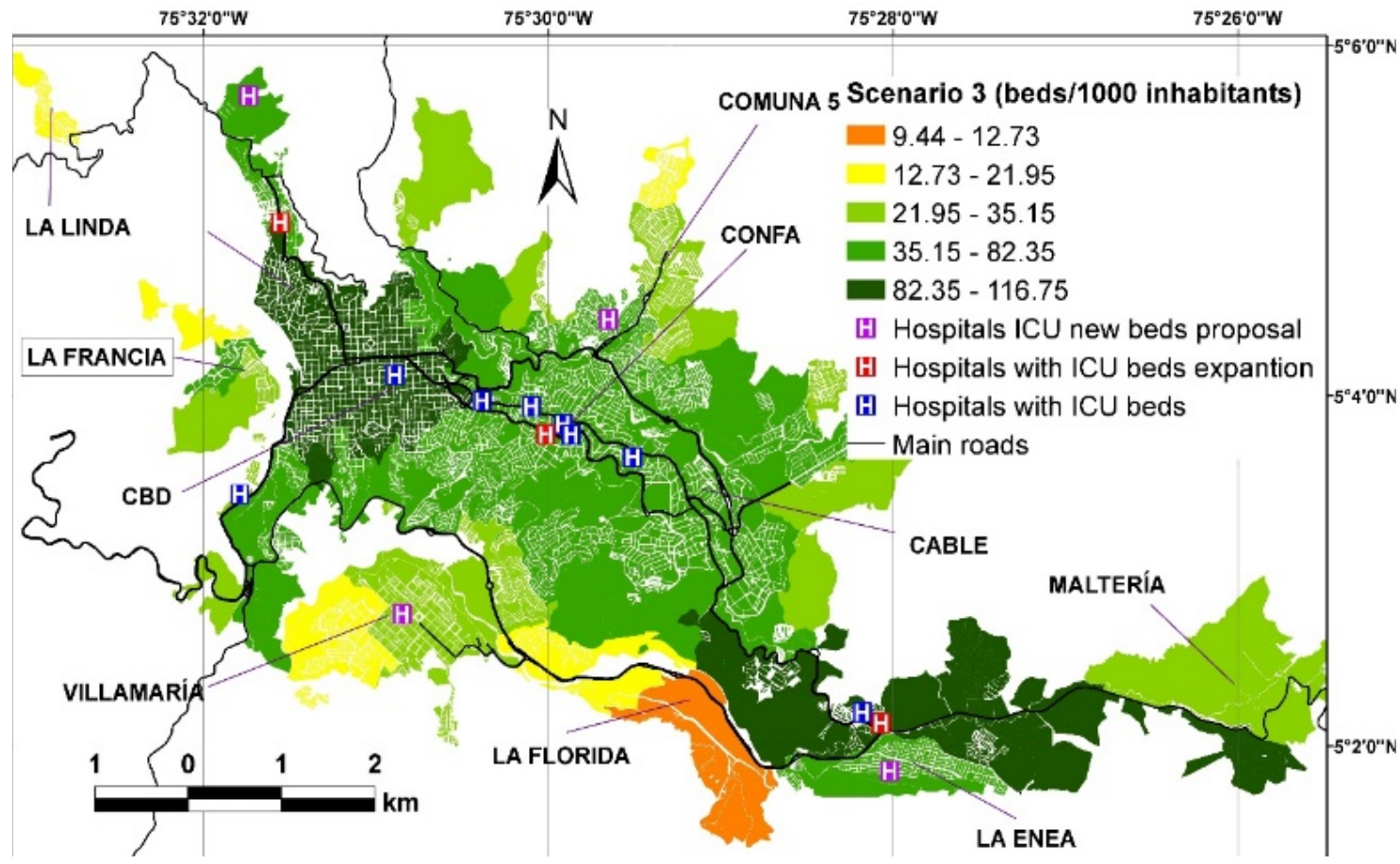

Source: Authors

Figure 9

Potential spatial accessibility gradient between scenario 3 and scenario 2

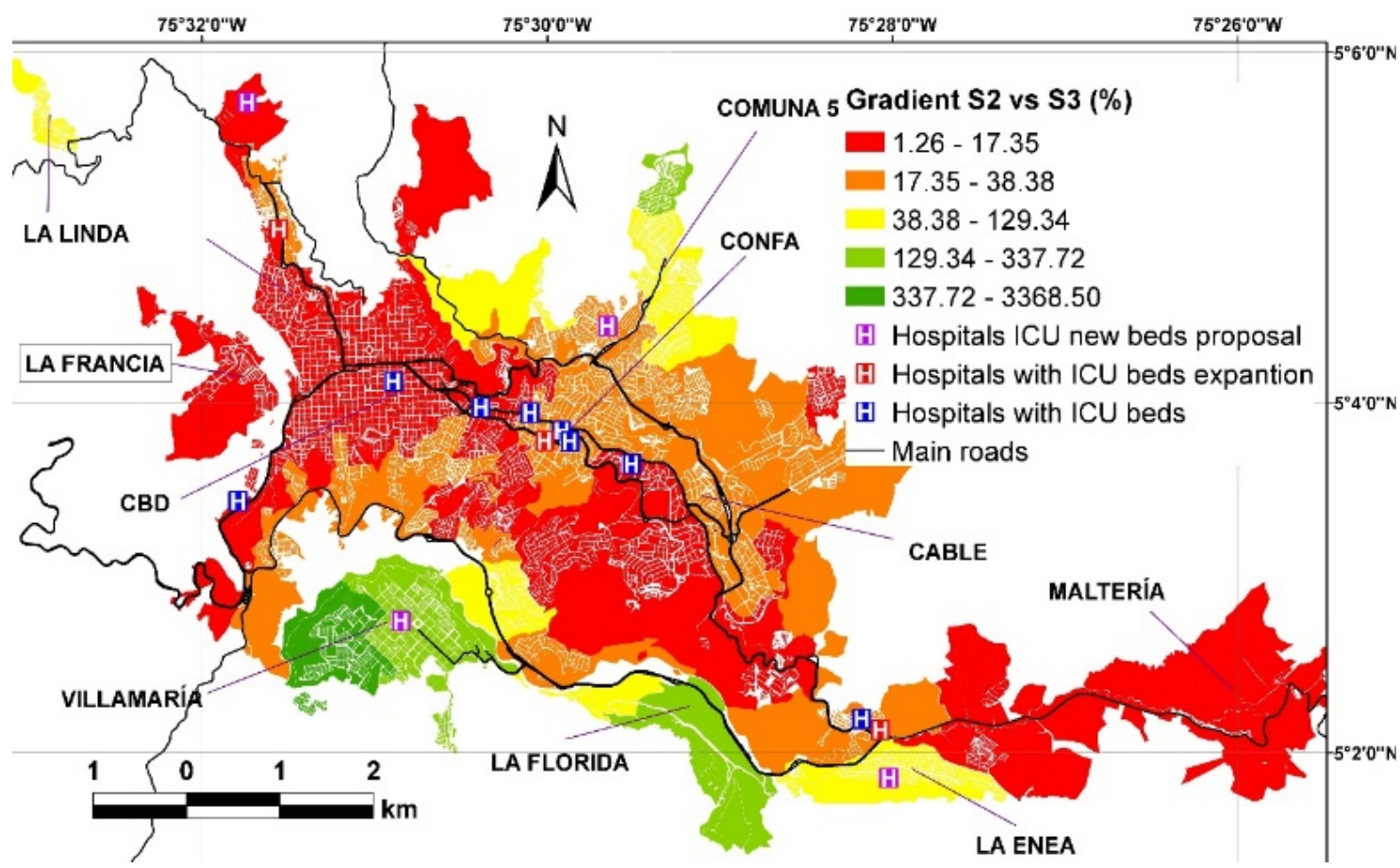

Source: Authors 
The urban planning models in relation to the health system of the analyzed area have not been implemented, let alone developed from a location perspective according to the real needs of the population. The previous situation surely happens in the majority of the Colombian, Latin American populations and in general, in those populations belonging to developing countries. Potential spatial accessibility is recognized as an important component, with strong theoretical and mathematical foundations in evaluating a population's general access to health care. Out of the large number of existing models to define the relationship between the supply of a service and its demand, the E2SFCA has allowed us to obtain results in units that may be easily interpreted by mayors or municipal administrators for their decision-making.

If the confirmed infected follow the current trend, it would be a major problem for the health system of the Manizales-Villamaría conurbation; despite the fact that to date, most cases have been imported the virus is already dispersed in this area, which will lead to the peak of need for severe and critical care at some point, regardless of so far, Colombia reports a mortality rate from COVID-19 lower than the world average. However, given the current capacity of the health system, this value could be higher. Despite this, the administrators of the health system in this region still hope that the health system will support this attack. The reality is that in all likelihood there will be problems of care for people who need an ICU, since according to the National projections, for this metropolitan area the value would reach 6200 patients, while local projections speak of a maximum of 3000. In addition to the above, the reflection of the referenced number of patients in need of ICU care, could be seen mainly dangerous in city inhabitants with physical condition problems such as cardiovascular problems, diabetes, respiratory diseases and hypertension, which have a percentage of mortality much higher where the mortality rate in these cases is between $6 \%$ to $11 \%$. In the case of the Manizales-Villamaría Metropolitan Area, around 88 thousand people have suffered morbidity, of which $3.54 \%$ have problems with high blood pressure and where the region population has had a long history of cardiovascular disease, with relatives who died before age 55 due to coronary etiology, $24 \%$ and a high level of smoking of $27.2 \%$, values that have not yet been taken into account in the analysis of ICU availability per thousand inhabitants, which will surely have an important effect on the solution that is intended to be implemented for the care of these patients.

Disparities in potential spatial accessibility are the result of the geographical configuration of ICU locations, the distribution of the population, and the transportation infrastructure that connects them. In this case of general quarantine, the transport infrastructure would hypothetically provide its greatest operational capacity, however, it is the possibility of accessing an ICU that would determine whether or not a certain segment of the population can access care of this type; that is, as observed in the results obtained, the average travel times in relation to the availability of the ICU, quickly stabilize, leading to the understanding that no matter how far a certain population is, its availability of ICU remains unchanged, a situation that could vary greatly if there were no mandatory quarantine or confinement condition.

Related to equity variables, it can be seen how through the scenarios, the ICU offer per thousand inhabitants is modified with the travel time. An ideal scenario of equity would reflect a constant supply of ICU for every thousand inhabitants and the same for each socioeconomic stratum throughout the travel time.

\section{Conclusions}

The research has three main contributions: i) application of the E2SFCA method in a health system where it has never been applied; ii) the results obtained by the E2SFCA method are compared with those obtained by analysis of minimum roads and their correlation with the economic conditions of the studied areas; iii) the results allowed identifying the areas that would be neglected in relation to each scenario, which is an essential step for the formulation of an effective intervention program. 
Carrying out this type of modeling within a GIS framework will provide city planners with some plausible and realistic results, which can be fed back as different strategies for strengthening the health care system are put in place and could also be used as evidence-based information. This can be particularly valuable in planning a future health care redistribution program for possible demographic changes. Given the above, it is considered vital to know, not only the characteristics of potential spatial accessibility to ICU care, but to establish how such care was developed, to be more prepared in future situations. It is noteworthy that the research methodology addressed in this study is fully replicable in areas, cities or regions, as far as you have the information on the supply of medical services, sociodemographic information, as well as the road network loaded with operational characteristics. (speed of operation). Likewise, this methodology can be applied for the study of potential spatial accessibility of other types of equipment, such as recreational areas, libraries, educational institutions, etc., which would be very useful for the definition of public policies when the pandemic situation is overcome.

In terms of equity, the hospital expansion scenario directly benefits the socioeconomic stratum 6 , which sees its ICU offer increase as travel time increases. On the other hand, socioeconomic strata 1 and 2 have a low supply of ICU which is constant despite the increase in travel time. Therefore, the spatial distribution of ICU beds generates inequality in the territory since it mainly benefits the middle and high socioeconomic strata, leaving the lowest strata with the least supply, however, this is largely due to the location of the hospitals in the base situation and in the expansion proposed by the mayor's office in scenario 2. Currently, given the location of hospitals with ICU availability, their ICU offer, population distribution, and transportation infrastructure, there is a clear inequity in the provision of critical patient care; likewise, given the expansion of ICU supply, the impact will be greater for the upper strata, in terms of the number of ICUs available per 1,000 inhabitants. It is identified that it is necessary for the San Antonio, San Isidro, San Cayetano and La Enea hospitals to be adequate with the ICU for the care of sectors that have low values of potential spatial accessibility to said service.

\section{Acknowledgements}

The authors thank the members of the Sustainable Mobility Research Group of Universidad Nacional de Colombia - Manizales Headquarters, especially the Eng. Jorge Montoya, Eng. Juan Manuel Gómez and the Industrial Engineering student Daniel González. The authors would also like to thank Julián Marín Hoyos for his assistance in the translation of this final manuscript. This research article "Full Paper" has been individually reviewed by academic peers.

\section{References}

Aday, L. A., \& Andersen, R. (1974). A Framework for the Study of Access to Medical Care. Health Services Research, 9(3), 208-220.

Ahmed, S., Adams, A. M., Islam, R., Hasan, S. M., \& Panciera, R. (2019). Impact of Traffic Variability on Geographic Accessibility to 24/7 Emergency Healthcare for the Urban Poor: A GIS study in Dhaka, Bangladesh. PLoS ONE, 14(9), 1-20. https://doi.org/10.1371/journal.pone.0222488

Anderson, R. M., Heesterbeek, H., Klinkenberg, D., \& Hollingsworth, T. D. (2020). How will country-based mitigation measures influence the course of the COVID-19 epidemic? The Lancet, 2019(20), 931-934. https://doi.org/10.1016/S0140-6736(20)30567-5

Batty, M. (2009). Accessibility: In search of a unified theory. Environment and Planning B: Planning and Design, 36(2), 191-194. https://doi.org/10.1068/b3602ed

Cardona, S. (2018). Propuesta metodológica para el cálculo de las penalidades por giro en modelos de accesibilidad. Masther Thesis, Manizales, Universidad Nacional de Colombia. 
Colombian Association of Critical Medicine and Intensive Care (Asociación Colombiana de medicina crítica y cuidado intensivo in spanish) (2020). Red AMCI de soporte crítico covid-19 (RASI-C-19). Colombia.

Cui, M., \& Levinson, D. (2019). Measuring full cost accessibility by auto. Journal of Transport and Land Use, 12(1), 649-672. https://doi.org/10.5198/jtlu.2019.1495

DANE - Departamento Administrativo Nacional de Estadística (2018). Censo Nacional de Población y Vivienda 2018. https://www.dane.gov.co/index.php/estadisticas-por-tema/demografia-y-poblacion/censonacional-de-poblacion-y-vivenda-2018/cuantos-somos

Dewulf, B., Neutens, T., De Weerdt, Y., \& Van de Weghe, N. (2013). Accessibility to primary care physicians in Belgium: An assessment of policies awarding financial assistance in shortage areas. BMC Family Practice, 14(122).

Dijkstra, E. W. (1959). A note on two problems in connexion with graps.pdf. Numerische Mathematik, 1, 269271.

Dummer, T. J. B., \& Parker, L. (2004). Hospital accessibility and infant death risk. Archives of Disease in Childhood, 89(3), 232-234. https://doi.org/10.1136/adc.2003.030924

Escobar, D.A., Cardona. S., \& Moncada, C.A. (2019). Alcance Geoespacial de Atención del Cuerpo de Bomberos. El Caso del Municipio de Manizales en Colombia. Información Tecnológica, 30(5), 283-290. http://dx.doi.org/10.4067/S0718-07642019000500283

Geurs, K. T., \& Ritsema, V. E. (2001). Accessibility measures: review and applications. Evaluation of accessibility impacts of land-use transport scenarios, and related social and economic impacts. RIVM Report, 787.

Guagliardo, M. F. (2004). Spatial accessibility of primary care: Concepts, methods and challenges. International Journal of Health Geographics, 3, 1-13. https://doi.org/10.1186/1476-072X-3-3

Haig, R. M., 1927. The Assignment of Activities to Areas in Urban Regions. In: Regional Survey of New York and its Environs. Committee on Regional Plan of New York and its Environs, New York.

Halden, D. (2011). The use and abuse of accessibility measures in UK passenger transport planning. Research in Transportation Business and Management, 2, 12-19. https://doi.org/10.1016/j.rtbm.2011.05.001

Handy, S. L., \& Niemeier, D. A. (1997). Measuring accessibility: An exploration of issues and alternatives. Environment and Planning A, 29(7), 1175-1194. https://doi.org/10.1068/a291175

Hansen, W. G. (1959). How Accessibility Shapes Land Use. Journal of the American Planning Association, 25(2), 73-76. https://doi.org/10.1080/01944365908978307

Holguín, J.M., Escobar, D.A., \& Moncada, C.A. (2018). Access to Emergency Medical Services: An Urban Planning Methodology for the Generation of Equity. Global Journal of Health Science, 10(6), 181-198. https://doi.org/10.5539/gjhs.v10n6p181

Hurd, R., 1903. Principles of City Land Values. Twentieth-Century Legal Treatises: UK. New York: Record and Guide.

Ingram, D. R. (1971). The Concept of Accessibility: A Search for an Operational Form. Regional Studies, 5(2), 101-107. https://doi.org/10.1080/09595237100185131

Ivorra, B. (2020). Application of the Be-CoDiS mathematical model to forecast the international spread of the 2019-20 Wuhan coronavirus outbreak. https://doi.org/10.13140/RG.2.2.31460.94081 
Joseph, A. E., \& Bantock, P. R. (1982). Measuring potential physical accessibility to general practitioners in rural areas: A method and case study. Social Science and Medicine, 16(1), 85-90. https://doi.org/10.1016/02779536(82)90428-2

Joseph, A. E., \& Phillips, D. R. (1984). Accessibility and utilization: geographical perspectives on health care delivery. Journal of the Royal College of General Practitioners, 34(265), 452.

https://doi.org/10.2307/633309

Kalogirou, S., \& Foley, R. (2006). Health, Place and Hanly: Modelling accessibility to hospitals in Ireland. Irish Geography, 39(1), 52-68. https://doi.org/10.1080/00750770609555866

Khan, A. A. (1992). An integrated approach to measuring potential spatial access to health care services. SocioEconomic Planning Sciences, 26(4), 275-287. https://doi.org/10.1016/0038-0121(92)90004-0

Kotavaara, O., Antikainen, H., \& Rusanen, J. (2011). Population change and accessibility by road and rail networks: GIS and statistical approach to Finland 1970--2007. Journal of Transport Geography, 19(4), 926935.

Kwan, M. (1998). Accessibility: A Comparative Analysis Using a Point-based Framework. GeoGraphical Analysis, 30(3), 191-216.

Levine, J. (2020). A century of evolution of the accessibility concept. Transportation Research Part D, 83, 102309. https://doi.org/10.1016/j.trd.2020.102309

Li, J., \& Heap, A. D. (2008). A Review of Spatial Interpolation Methods for Environmental Scientists. Geoscience Australia, Record 2008/23, 137.

Love, D., \& Lindquist, P. (1995). The geographical accessibility of hospitals to the aged: A geographic information systems analysis within Illinois. Health Services Research, 29(6), 629-651.

Lucas, K., van Wee, B., \& Maat, K. (2016). A method to evaluate equitable accessibility: combining ethical theories and accessibility-based approaches. Transportation, 43(3). https://doi.org/10.1007/s11116-0159585-2

Luo, W., \& Qi, Y. (2009). An enhanced two-step floating catchment area (E2SFCA) method for measuring spatial accessibility to primary care physicians. Health and Place, 15(4), 1100-1107.

https://doi.org/10.1016/j.healthplace.2009.06.002

Luo, W., \& Wang, F. (2003). Measures of spatial accessibility to health care in a GIS environment: Synthesis and a case study in the Chicago region. Environment and Planning B: Planning and Design, 30(6), 865-884. https://doi.org/10.1068/b29120

Luo, W., \& Whippo, T. (2012). Variable catchment sizes for the two-step floating catchment area (2SFCA) method. Health and Place, 18(4), 789-795. https://doi.org/10.1016/j.healthplace.2012.04.002

McGrail, M. R. (2012). Spatial accessibility of primary health care utilising the two-step floating catchment area method: An assessment of recent improvements. International Journal of Health Geographics, 11, 1-12. https://doi.org/10.1186/1476-072X-11-50

McGrail, M. R., \& Humphreys, J. S. (2014). Measuring spatial accessibility to primary health care services: Utilising dynamic catchment sizes. Applied Geography, 54, 182-188.

https://doi.org/10.1016/j.apgeog.2014.08.005 
Moncada, C. A., Cardona, S., \& Escobar, D. A. (2018). Saving Travel Time as an Urban Planning Instrument. Case Study: Manizales, Colombia. Modern Applied Science, 12(6), 44. https://doi.org/10.5539/mas.v12n6p44

Monsalve, S., Rucinque, D. S., Polo, L., \& Polo, G. (2016). Evaluación de la accesibilidad espacial a los puestos de la campaña de vacunación antirrábica en Bogotá, Colombia. Biomedica, 36(3), 447-453. https://doi.org/10.7705/biomedica.v36i3.3074

Moorin, R. E., \& Holman, C. D. A. J. (2006). The effects of socioeconomic status, accessibility to services and patient type on hospital use in Western Australia: A retrospective cohort study of patients with homogenous health status. BMC Health Services Research, 6, 1-10. https://doi.org/10.1186/1472-6963-674

National Institute of Health (Instituto Nacional de Salud in spanish) (2020). COVID-2019 en Colombia. Retrieved from: https://www.ins.gov.co/Noticias/Paginas/Coronavirus.aspx

Neutens, T. (2015). Accessibility, equity and health care: Review and research directions for transport geographers. Journal of Transport Geography, 43, 14-27. https://doi.org/10.1016/j.jtrangeo.2014.12.006

Páez, A., Scott, D. M., \& Morency, C. (2012). Measuring accessibility: Positive and normative implementations of various accessibility indicators. Journal of Transport Geography, 25, 141-153. https://doi.org/10.1016/j.jtrangeo.2012.03.016

Pan, J., Liu, H., Wang, X., Xie, H., \& Delamater, P. L. (2015). Assessing the spatial accessibility of hospital care in Sichuan Province, China. Geospatial Health, 10(2), 261-270. https://doi.org/10.4081/gh.2015.384

Pirie, G. H. (1979). Measuring Accessibility: A Review and Proposal. Environment and Planning A: Economy and Space, 11(3), 299-312. https://doi.org/10.1068/a110299

Prasetiyowati, S. S., Imrona, M., Ummah, I., \& Sibaroni, Y. (2016). Prediction of public transportation occupation based on several crowd spots using ordinary kriging method. Journal of Innovative Technology and Education, 3(1), 93-104. https://doi.org/10.12988/jite.2016.6723

Radke, J., \& Mu, L. (2000). Spatial decompositions, modeling and mapping service regions to predict access to social programs. Geographic Information Sciences, 6(2), 105-112. https://doi.org/10.1080/10824000009480538

Republic of Colombia. Decreto 417 del 17 de marzo de 2020. Recuperado de: https://dapre.presidencia.gov.co/normativa/normativa/DECRETO\%20417\%20DEL\%2017\%20DE\%20MARZ O\%20DE\%202020.pdf

Rojas, D. \& Caicedo, B. (2017). Geographical Accessibility to Obstetric and Neonatal Care and its Effect on Early Neonatal Mortality in Colombia,2012-2014. Med Unab, 20(1), 7-18.

Shah, T. I., Bell, S., \& Wilson, K. (2016). Spatial accessibility to health care services: Identifying under-serviced neighbourhoods in Canadian urban areas. PLOS ONE, 11(12), 1-22.

https://doi.org/10.1371/journal.pone.0168208

Vega, A. (2011). A multi-modal approach to sustainable accessibility in Galway. Regional Insights, 2(2), 15-17.

Wan, N., Zou, B., \& Sternberg, T. (2012). A three-step floating catchment area method for analyzing spatial access to health services. International Journal of Geographical Information Science, 26(6), 1073-1089. https://doi.org/10.1080/13658816.2011.624987 
Wang, H., Wang, Z., Dong, Y., Chang, R., Xu, C., Yu, X., ... Cai, Y. (2020). Phase-adjusted estimation of the number of Coronavirus Disease 2019 cases in Wuhan, China. Cell Discovery, 6(1), 4-11. https://doi.org/10.1038/s41421-020-0148-0

Wang, F. (2012). Measurement, Optimization, and Impact of Health Care Accessibility: A Methodological Review. Annals of the Association of American Geographers, 102(5), 37-41. https://doi.org/10.1080/00045608.2012.657146

Wang, J., Du, F., Huang, J., \& Liu, Y. (2020). Access to hospitals: Potential vs. observed. Cities, 100(January). https://doi.org/10.1016/j.cities.2020.102671

Whitehead, J., Pearson, A. L., Lawrenson, R., \& Atatoa-Carr, P. (2020). Defining general practitioner and population catchments for spatial equity studies using patient enrolment data in Waikato, New Zealand. Applied Geography, 115(January), 102137. https://doi.org/10.1016/j.apgeog.2019.102137

World Health Organization (2020a). Coronavirus disease (COVID-19) Pandemic. Retrieved from: https://www.who.int/emergencies/diseases/novel-coronavirus-2019

World Health Organization (2020b). Coronavirus disease (COVID-19) Situation Dashboard. Data accesed 23/04/2020. Retrieved from: https://covid19.who.int/

Younes, C., Escobar, D. A., \& Holguín, J. M. (2016). Equidad, accesibilidad y transporte. Aplicación explicativa mediante un análisis de accesibilidad al sector universitario de manizales (Colombia). Informacion Tecnologica, 27(3), 107-118. https://doi.org/10.4067/S0718-07642016000300010

Zuluaga, J. D., \& Escobar, D. A. (2017). Análisis de accesibilidad territorial de la región noroccidente de Colombia. Revista Espacios, 38(6).

Esta obra está bajo una Licencia Creative Commons Attribución-NoCommercial 4.0 International

\section{(cc) BY-NC}

